\title{
Effect of Different Solvent on Phytochemical Content, Tyrosinase Inhibition and Antioxidant Activities of Campolay (Pouteria campechiana kunth. [Baehni.])
}

\author{
Sani Nurlaela Fitriansyah ${ }^{1,2 *}$ (D), R. Hartati $^{1}$, I. Fidrianny ${ }^{1}$ \\ ${ }^{1}$ Department of Pharmaceutical Biology, School of Pharmacy, Bandung Institute of Technology, Bandung, Indonesia; ${ }^{2}$ Department \\ of Pharmaceutical Biology, Indonesian School of Pharmacy (Sekolah Tinggi Farmasi Indonesia), Bandung, Indonesia
}

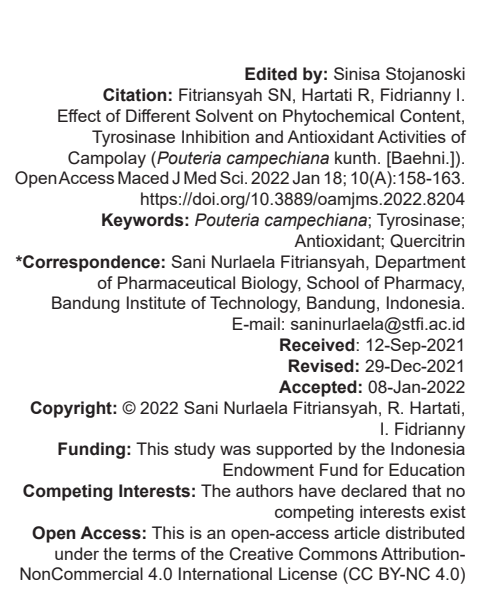

Abstract

BACKGROUND: Pouteria campechiana leaves are reported to have phenol and flavonoid compounds. Phenolic and flavonoid compounds can act as tyrosinase inhibitor and antioxidant.

AIM: The purpose of this study was to compare phytochemical content, tyrosinase inhibition, antioxidant activities, and determine of marker compound from P. campechiana leaves extract with different polarities solvent.

METHODS: In addition, the content of marker compound from P. campechaina leaves extract was determined by HPLC.

RESULTS: The highest total phenolic content (TPC) $7.83 \mathrm{GAE} / 100 \mathrm{~g}$ extract, IC50 of tyrosinase $171.512 \pm 1.352$ and IC50 of DPPH $0.968 \pm 0.008$ was given by ethanolic extract (DE). Meanwhile ethyl acetate extract (DEA) had the highest of total flavonoid content $2.544 \pm 0.554 \mathrm{QEA} / 100 \mathrm{~g}$ extract. The TPC correlated with tyrosinase inhibitory activity and antioxidant activity.

CONCLUSION: Quercitrin was as marker compound from P. campechiana leaves extract, and quercitrin content in the DEA of P. campechiana leaves was $3.539 \%$, while in the DE was $0.153 \%$.

\section{Introduction}

Exposure of UV light can produce Reactive Oxidative Singlet (ROS). If the mechanism action of ROS is not inhibited, it will increase the tyrosinase action [1]. Tyrosinase is enzyme that plays the role in biosynthesis of melanin in plant and mammalian cell, including human skin [2]. The mechanism action of tyrosinase enzyme divided into two, namely monophenolase activity using L-tyrosine substrate and diphenolase using L-DOPA substrate [2], [3]. Diphenolase activity will produce ortho-quinone, meanwhile melanin will be produced by non-enzymatic reaction. This process is called melanogenesis [4].

Antioxidants compounds can inhibit the reaction of free radicals. An example of a free radical is ROS which is found in the skin. When antioxidant can inhibit reaction of ROS which is caused by UV light exposure on the skin, it will reduce tyrosinase enzyme activity. Phenolic acid [5], flavonol [6], and stilbenoide [7] were antioxidant compounds as well as tyrosinase inhibitors.
Medicinal plants are a source of raw material which contain phenolic, flavonoids and other polyphenols. The biological activity of a plant can be caused by the presence of phytochemical compound. The solvent used and extraction method will affect the phytochemical compound resulting. Pouteria campechiana is one of the medicinal plants in Sapotaceae family. In Indonesia, $P$. campechiana was called as campolay. $P$. campechiana fruits extract contains gallic acid, myricitrin and cathecin which act as antioxidant compounds [8]. In addition, taxifolin, quercetin glycoside and myricetin glycoside were found in $P$. campechiana leaves which its toxicity had been tested [9]. The comparison of chemical content, tyrosinase inhibitory activity, antioxidant activity of $P$. campechiana leaves extract have not been reported with different solvent polarity levels.

In this study, the total chemical content was calculated, inhibitory of tyrosinase and antioxidant activities were tested, then marker compound from selected extract of $P$. campechiana was identified and determined. 


\section{Experimental}

\section{Material}

P. campechiana leaves were collected from Bandung, West Java, Indonesia in December 2020.

\section{Chemical material}

DPPH (Sigma Aldrich), tyrosinase enzyme (T3824-25KU, Sigma Aldrich), L-DOPA (Sigma Aldrich), quercetin, kaemferol, apigenin, gallic acid, chlorogenic acid, luteolin 7-O glycoside, and rutin which were obtained from Sigma Aldrich, quercitrin (Markherb), methanol pro analysis, ethanol 96\%, ethyl acetate, n-hexane, Folin-Ciocalteu reagent, aluminum chloride and other chemical materials which used in this study were analytical grade.

\section{Preparation extract}

Extraction was conducted using Soxhlet with increasing polarity solvent, ranging from nonpolar (n-hexane), semi-polar (ethyl acetate), and polar solvent (ethanol $96 \%$ ). $400 \mathrm{~g}$ of $P$. campechiana leaves powder was extracted with n-hexane, the filtrate and residue are separated. The residue was dried, and then extracted with ethyl acetate. Finally, the residue was extracted using ethanol $96 \%$. Each extract was thickened using rotary evaporator with a temperature of $50^{\circ} \mathrm{C}$ to produce n-hexane extract (DN), ethyl acetate extract (DEA), and ethanol $96 \%$ extract (DE). Each extraction process with Soxhlet was carried out triplicate. The use of this extraction method is expected to be more effective in separating the phytochemical content.

\section{Total phenolic content (TPC)}

Determination of TPC using modification of Pourmorad's method [10]. Each extract was tested triplicate. The test was measured at a wavelength of $765 \mathrm{~nm}$. TPC was calculated by gallic acid calibration curve with concentration in the range of $10-250 \mu \mathrm{g} / \mathrm{ml}$ and expressed as gallic acid equivalent (GAE) per $100 \mathrm{~g}$ extract (g GAE/100 g extract).

\section{Total flavonoid content (TFC)}

Determination of TFC using of Chang's method modified [11]. Each extract was tested triplicate. The test was investigated at a wavelength of $415 \mathrm{~nm}$. TFC was calculated by quercetin calibration curve with concentration ranged from 25 to $250 \mu \mathrm{g} / \mathrm{ml}$ and presented as quercetin equivalent (QE) per $100 \mathrm{~g}$ extract (g QE/100 g extract).

\section{Tyrosinase inhibitory activity}

Determination of tyrosinase inhibitory activity using as spectrophotometer in 96-well plates (Biologix ${ }^{\circledR}$ ) following the procedure of Masuda's method [12] with slight modification. Tyrosinase inhibitory activity was determined by diphenolase mechanism, with L-Dopa as substrate. Standard of tyrosinase inhibitor (kojic acid) were dissolved in phosphate buffer $(\mathrm{pH}$ 6.8) which contained DMSO 5\%. The enzyme concentration used was 300 unit $/ \mathrm{ml}$. Absorbance was investigated at $\lambda 475 \mathrm{~nm}$. Concentration of DN, DEA and DE $1000 \mu \mathrm{g} / \mathrm{ml}$ were carried out for testing tyrosinase inhibitory activity. Then, 10 concentration series was prepared from the selected sample to find the $\mathrm{IC}_{50}$ value.

\section{Antioxidant activity}

Determination of antioxidant activity was used modified Blois's method [13]. The free radical DPPH with a concentration of $39.4 \mu \mathrm{g} / \mathrm{ml}$ in methanol. The standard was ascorbic acid. Absorbance measurement at $\lambda 517 \mathrm{~nm}$ using a UV-Vis spectrophotometer (Beckman Coulter DU 720). Extracts and standard were performed in three replications. The final parameter used as antioxidant activity was antioxidant activity index $(\mathrm{AAI})$, which applied the formula $\mathrm{AAI}=$ (Final concentration of DPPH $[\mu \mathrm{g} / \mathrm{ml}]) / / C_{50}(\mu \mathrm{g} / \mathrm{ml})[14]$.

\section{Statistical analysis}

The results were presented with the mean \pm SD value from three repetitions of the test, using MS excel software to evaluate the results of the $I_{50}$ value. Statistical analysis was also used to see the correlation between the TPC and TFC to tyrosinase inhibitory and antioxidant activities with Pearson's method in Minitab-19 application.

\section{Identification of marker compound from selected extract}

Identification of marker compound was carried out qualitatively. The first method using TLC co-chromatography to compare the Retardation factor (Rf) values with various standard compounds. The second method used was HPLC (LC-20AD) by comparing with quercitrin as standard compound selected based on the TLC co-chromatography. The stationary phase in HPLC used LiChrospher $^{\circledR} 100$ RP-C18 $5 \mu \mathrm{m}$ (length 100 mm, diameter 4 mm, 20 mm in column [Merck]). The mobile phase used was $0.01 \%$ $\mathrm{H}_{3} \mathrm{PO}_{4}$ (eluent A) dan methanol (eluent B). Eluent B, $2.5 \min 40 \%, 2.51$ to $7 \min 60 \%, 7.01-12 \min 70 \%$, and $40 \%$ for linier gradient from 12 to $15 \mathrm{~min}$. Flow rate used $1 \mathrm{ml} / \mathrm{min}$, (CTO-20A pump, Shimadzu, Japan). Injection volume $20 \mu \mathrm{l}$. Detector used $366 \mathrm{~nm}$ (Detector UV/Vis SPD-20A, Shimadzu, Japan). The parameter used was 
retention time from standard compound (quercitrin) and sample. Sample and quercitrin were diluted in methanol with $50.000 \mu \mathrm{g} / \mathrm{ml}$ for DE, $10.000 \mu \mathrm{g} / \mathrm{ml}$ for DEA and $500 \mu \mathrm{g} / \mathrm{ml}$ for quercitrin.

\section{Determination of marker content}

Determination of marker content from selected extract used the one-point method. Calculation the content of marker was by comparing the area under curve (AUC) of marker in extract and AUC of standard compound.

\section{Results and Discussion}

\section{Extraction of $P$. campechiana leaves}

Extraction was carried out by Soxhlet with different polarity solvents. The compound in the crude drug will be derived based on polarity. The yield obtained from DN, DEA and DEs of $P$. campechiana leaves was showed in Table 1. The yield of the extracts indicated amount of the secondary metabolite which was extracted in each solvent with different polarity. DE had the largest yield compared to DN and DEA. This result showed that extraction of $P$. campechiana leaves by Soxhlet with ethanol $96 \%$ could attract more metabolite from $P$. campechiana leaves.

Table 1: The yield of Pouteria campechiana leaves extracts

\begin{tabular}{ll}
\hline Sample & Yield of extract \\
& ( $\mathrm{g}$ extract/100 $\mathrm{g}$ dried leaves) \\
\hline DN & 7.24 \\
DEA & 5.25 \\
DE & 23.00 \\
\hline DN: $n$-hexane extract, DEA: Ethyl acetate extract, DE: Ethanol extract.
\end{tabular}

\section{Determination of phytochemical content}

Determination of phytochemical content was conducted for TPC and TFC. This is based on phenolic and flavonoid plays a role in tyrosinase inhibitory and antioxidant activities.

TPC was calculated using gallic acid curve with linier regression equation $y=0.0062 x+0.0592$; $\mathrm{R}^{2}=0.999$ (Figure 1) and presented by $\mathrm{g}$ GAE/100 $\mathrm{g}$ extract. It has no report regarding TPC and TFC in $P$. campechiana leaves extract using the multilevel extraction method by Soxhlet. DE had higher TPC and significantly different compared to DN and DEA $(p<0.05)$. The TPC of ethanol leaves extract was higher than DN and DEAs (Figure 3). Phenolic compound is a group of secondary metabolites in plants. The phenolic group included polyphenols. Polyphenols included flavonoids, phenolic acids, stilbenoid and lignan [15]. The phenolic group which has more $\mathrm{OH}$ groups showed high polarity and will be more effective if extracted with a

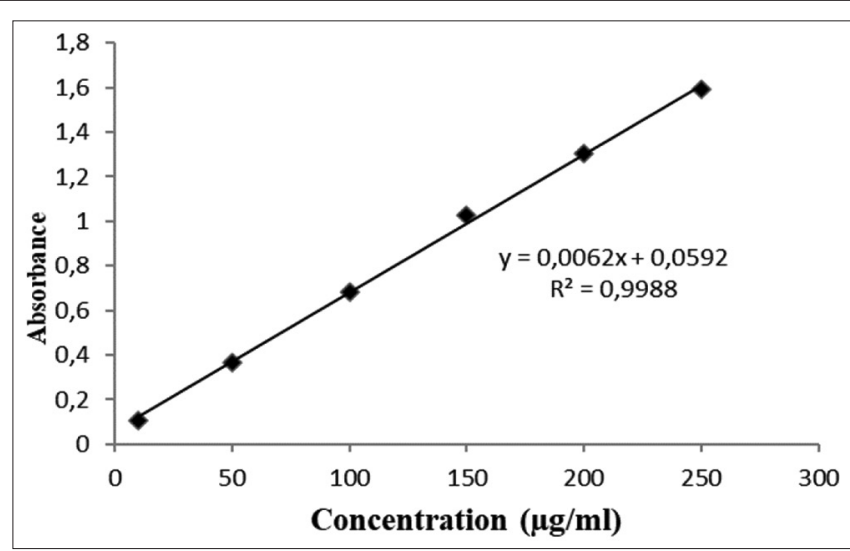

Figure 1: Calibration curve of gallic acid

polar solvent, such as ethanol. The fewer $\mathrm{OH}$ groups in phenolic group will be extracted with semipolar solvents such as ethyl acetate.

The TFC was determined based on the quercetin standard curve [Figure 2], $\mathrm{y}=0.0061 \mathrm{x}+$ $0.0796 ; R^{2}=0.994$ and exposed with $\mathrm{g} Q \mathrm{QE} / 100 \mathrm{~g}$ extract. DEA showed higher TFC and significantly different compared to DN and DE $(p<0.05)$. It showed the DEA had the highest TFC compared to DE and DNs. This means, that ethyl acetate solvent was more effective for extracting flavonoids from $P$. campechiana leaves. Based on the structure, the flavonoid group can be divided into flavones group such as apigenin, flavonols group such as quercetin, quercitrin and myricitrin, flavan group, flavanol and anthocyanidin group [16].

\section{Tyrosinase inhibitory activity}

The tyrosinase inhibitory activity of $P$. campechiana leaves extract was expressed in Table 2. Determination of tyrosinase inhibitory activity using modification method of Masuda [12]. Kojic acid was used as tyrosinase inhibitor. Inhibitory of tyrosinase activity from $\mathrm{DE}, \mathrm{DEA}$ and DNs of $P$. campechiana leaves were the first time reported. The result of the study showed that $D E$ had the highest tyrosinase inhibitory activity compared to DEA and DN. The DN had lowest of tyrosinase inhibitory activity which was $15.078 \pm 1.785$ at $1000 \mu \mathrm{g} / \mathrm{ml}$. Therefore, DN was not continued to determine the $\mathrm{IC}_{50}$ tyrosinase inhibitory value. The difference in tyrosinase inhibitory activity in DE, DEA and DN extract could be due to differences in phytochemical content that extracted in each extract. Extraction methods with different solvent polarity levels can extract different chemical constituents. Differences in the chemical structure of each compound will affect the strength of tyrosinase inhibitory and antioxidant activities [17]. Phenols and flavonoids can contribute to antioxidant and tyrosinase inhibitory activity [18]. The number of hydroxy groups can increase antioxidant activity and tyrosinase inhibitory activity [1]. According to the literature, Manilkara zapota belong to Sapotaceae family gave tyrosinase inhibitory activity. The chemical constituent of Manilkara zapota belonging to the triterpenoids, sterols, flavonoids, and phenolic groups presented tyrosinase inhibitory activity with 
Table 2: $\mathrm{IC}_{50}$ of DPPH and $\mathrm{IC}_{50}$ of Tyrosinase Pouteria campechiana leaves extract

\begin{tabular}{lll}
\hline Extract & $\mathrm{IC}_{50} \mathrm{DPPH}(\mu \mathrm{g} / \mathrm{ml})$ & $\mathrm{IC}_{50}$ Tyrosinase $(\mu \mathrm{g} / \mathrm{ml})$ \\
\hline DN & $8.602 \pm 1.226$ & - \\
DEA & $1.040 \pm 0.101$ & $828.537 \pm 0.962$ \\
DE & $0.968 \pm 0.008$ & $176.553 \pm 4.613$ \\
Ascorbic acid & $0.570 \pm 0.002$ & - \\
Kojic acid & - & $10.513 \pm 0.707$ \\
\hline DN: $n$-hexane extract, DEA: Ethyl acetate extract, DE: Ethanol extract.
\end{tabular}

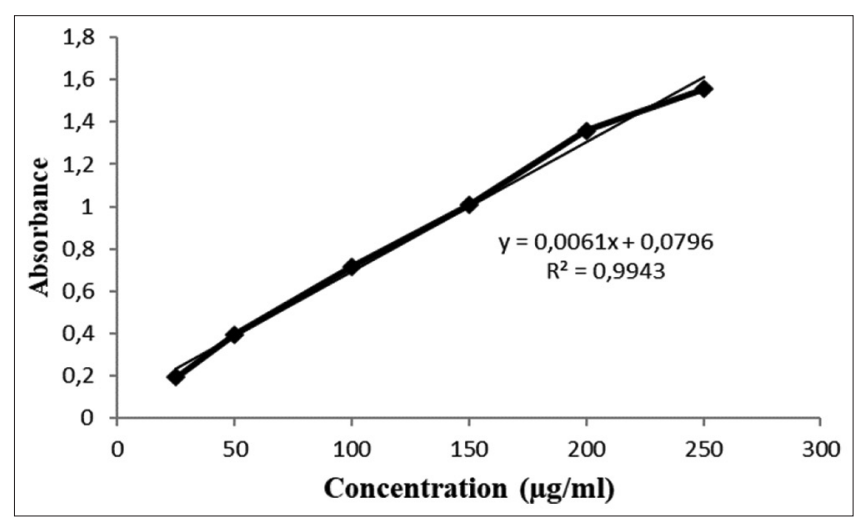

Figure 2: Calibration curve of quercetin

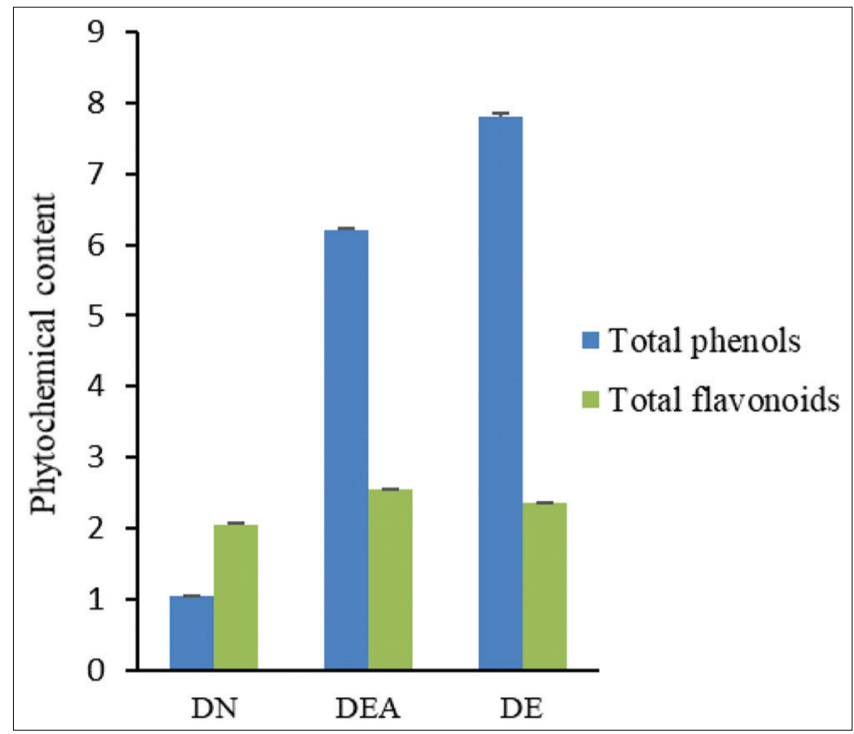

Figure 3: Phytochemical content of Pouteria campechiana leaves extract

monophenolase and diphenolase. Triterpenoids showed strong inhibitory of tyrosinase activity with monophenolase mechanism. Myricitrin which was a flavonoids glycoside from Manilkara zapota leaves extract, showed weak of tyrosinase inhibitory activity [19].

\section{Antioxidant activity}

Antioxidant activity of $P$. campechiana leaves extract can be seen in Table 3 and Figure 4. The value of antioxidant activity was presented in $\mathrm{IC}_{50}$ and AAI. Ascorbic acid was used as standard. DPPH used as free radical. According to Scherer and Godoy [14], if AAI $<0.5$ was weak antioxidant, $0.5-1$ medium antioxidant, 1-2 strong antioxidant and more than 2 classified as very strong antioxidant. The highest $\mathrm{AAl}$ value was
Table 3: Correlation of phytochemical content with tyrosinase inhibitory and antioxidant activities

\begin{tabular}{lll}
\hline Activity parameter & \multicolumn{2}{l}{ Pearson's correlation coefficient $(r)$} \\
\cline { 2 - 3 } & TPC & TFC \\
\hline AAl & $0.981^{* *}$ & $-0.978^{* *}$ \\
IC ${ }_{50}$ tyrosinase & $-1.00^{* *}$ & $0.999^{* *}$ \\
\hline TPC: Total phenolic content, TFC: Total flavonoid content, AAl: Antioxidant activity index.
\end{tabular}

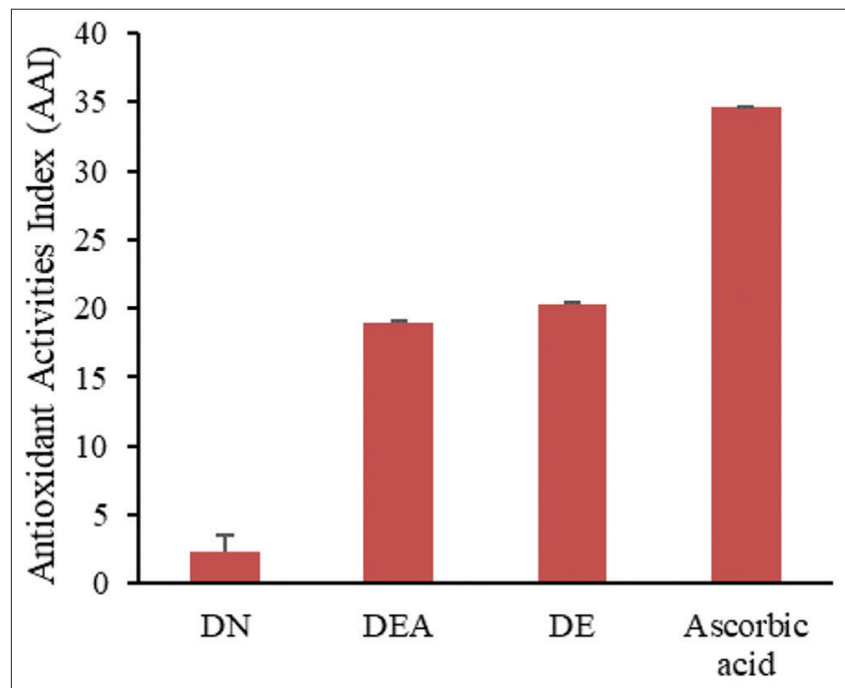

Figure 4: AAl of Pouteria campechiana leaves extract

in DE, followed by DEA and finally by DN extract of $P$. campechiana leaves. However, if classification based on the AAI value, the DE, DEA and DN of $P$. campechiana leaves were classified as very strong antioxidant. The AAI of DE, DEA, and DN was lower than the AAI of ascorbic acid. The phenolic group can contribute to antioxidant activity [20]. The position of the $\mathrm{OH}$ group on flavonoids can affect the antioxidant activity. The presence of $\mathrm{OH}$ groups in ring $\mathrm{B}$, at $\mathrm{C}-3$ and ortho-hydroxy groups in ring $A$ and $B$ can increase antioxidant activity. In addition to the $\mathrm{OH}$ group, the presence of a double bond at the C2-C3 position, and the presence of a carbonyl group at C4 can also increase antioxidant activity [16].

\section{Correlation of total phenolic and flavonoid content with tyrosinase inhibitory and antioxidant activities}

TPC had a positive and significant correlation with AAI DPPH. The TPC also gave negative and significant correlation with $\mathrm{IC}_{50}$ tyrosinase (Table 3 ). This mean that when TPC increase, the AAI DPPH increase which showed high antioxidant activity. Increasing in TPC will correlate with decreasing in $\mathrm{IC}_{50}$ of tyrosinase, which presented high tyrosinase inhibitory activity. This correlation result was in line with the results of the study which showed that ethanolic extract had the higher TPC than the DEA and DNs.

\section{Identification of marker compound}

Marker compound was used to control the consistency of crude drug, extract or product of the 
extract. The results of the identification of compounds in the ethanol and DEAs by TLC co-chromatography (Figure 5) showed that there were spots of $\mathrm{DE}$ and DEA which had the same $\mathrm{Rf}$ value with quercitrin (0.38). The retention time of one peak in DE and DEA chromatograms coincided with the retention time on the quercitrin. Based on the HPLC chromatogram, quercitrin was dominant compound in DE and DEA. Then quercitrin was stated as marker compound in $P$. campechiana leaves extract. The HPLC chromatogram of DE and DEA of $P$. campechiana leaves and quercitrin standard was displayed in Figure 6. It confirmed the identification of marker compound of DE and DEA by TLC.

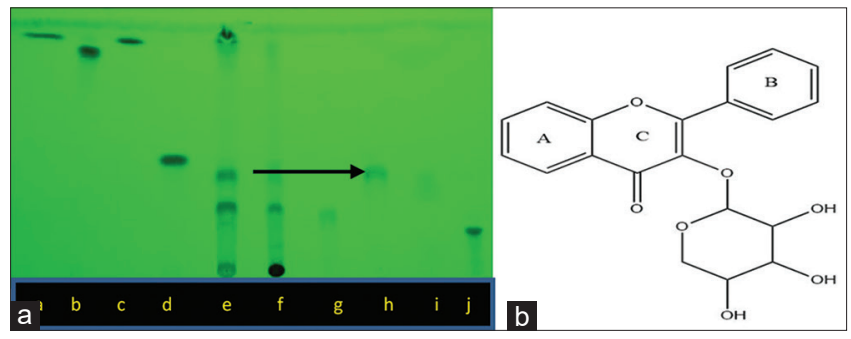

Figure 5: (a) TLC co-chromatography of DE and DEA with standard compounds: a. kaempferol, b. quercetin, c. apigenin, d. gallic acid, e. $D E A, f$. DE, g. chlorogenic acid, h. quercitrin, i. luteolin 7-O glycoside, $j$. rutin, monitoring under UV light $\lambda 254 \mathrm{~nm}$; (b) quercitrin structure

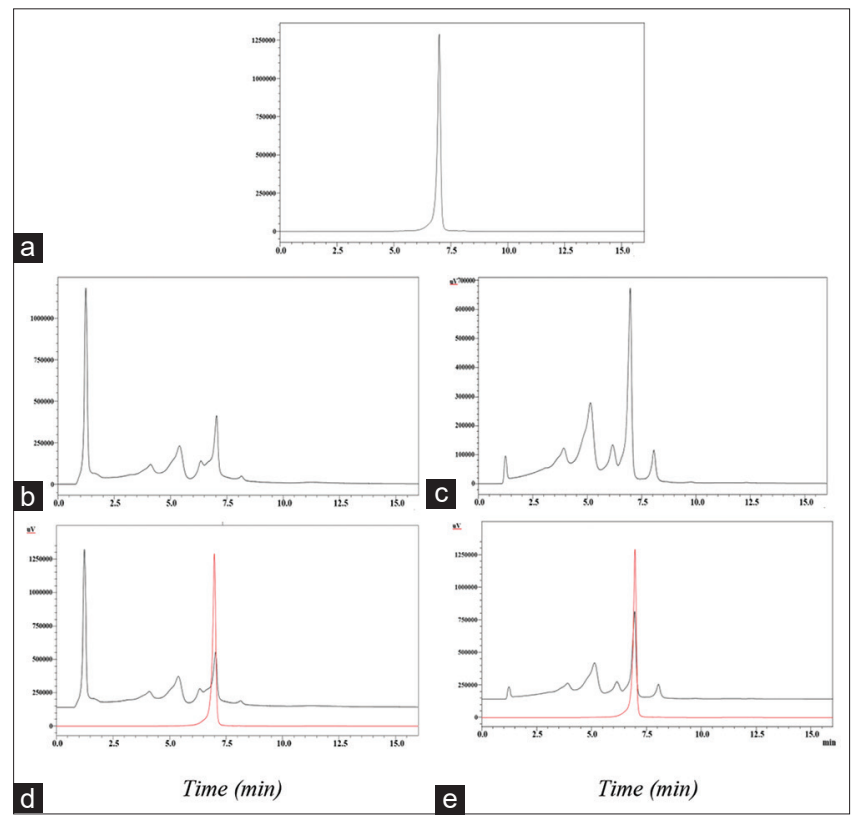

Figure 6: (a) Chromatogram HPLC of quercitrin; (b) DE; (c) DEA; (d) overlay quercitrin with $D E$; (e) overlay quercitrin with $D E A$

\section{Marker compound content in P. campechiana leaves extract}

Determination of marker compound content in DE and DEA were used one point method and the result showed in Table 4 . The content of quercitrin in DEA was higher than in DE. Quercitrin is a compound that belongs to the flavonoid glycoside group. The benefit of quercitrin include being able to act as an
Table 4: Quercitrin content in ethanol and DEA of Pouteria campechiana leaves

\begin{tabular}{lllll}
\hline Sample & Concentration & Retention time $(\mathrm{min})$ & AUC & Quercitrin content \\
\hline Quercitrin & $500 \mu \mathrm{g} / \mathrm{ml}$ & 6.998 & 15032928 & - \\
DE & $50000 \mu \mathrm{g} / \mathrm{ml}$ & 6.930 & 2295223 & $0.153 \%$ \\
DEA & $10000 \mu \mathrm{g} / \mathrm{ml}$ & 6.972 & 10639291 & $3.539 \%$ \\
\hline \multicolumn{4}{l}{ AUC: Area under curve, DE: Ethanol extract, DEA: Ethyl acetate extract. }
\end{tabular}

antioxidant, antibacterial [21] and can protect the skin from exposure to UV B rays [22].

\section{Conclusion}

P. campechiana leaves extract had a potential as an antioxidant and tyrosinase inhibitor. DE of $P$. campechiana leaves had the highest potential for tyrosinase inhibitory and antioxidant activities. The highest TPC was in the DE and the highest TFC was in the DEA of $P$. campechiana leaves. TPC have a correlation with tyrosinase inhibitory and antioxidant activities. Quercitrin was chosen as a marker compound from $P$. campechiana leaves extract and the quercitrin content in the DEA was higher than in DE. Subsequent research will isolate compounds that can contribute to tyrosinase inhibitory and antioxidant activities.

\section{Acknowledgment}

The Author would like to thank to the Indonesia Endowment Fund for Education (LPDP) which has funded this research with contract number 2020032130798. Thanks are also extended to ITB and STFI who facilitated the instruments in carrying out this research, to Nurma Sabila who has helped in this research work for HPLC.

\section{References}

1. Chunhakant S, Chaicharoenpong C. Antityrosinase, antioxidant, and cytotoxic activities of phytochemical constituents from Manilkara zapota L. Bark. Molecule. 2019;2798(24):1-19. https://doi.org/10.3390/molecules24152798 PMid:31370334

2. Muddathir AM, Yamuchi K, Batubara I, Mohieldin EA, Mitsunaga T. Anti-tyrosinase, total phenolic content and antioxidant activity of selected Sundanese medicinal plant. South Afr J Bot. 2017;/09:9-15. http://dx.doi.org/10.1016/j. sajb.2016.12.013

3. Prota G. An introduction to melanin research. In: Prota, G. editor. Melanins and Melanogenesis. San Diego, CA, USA: Academic Press; 1992. p. 1-9.

4. Ferrer S, Lopez AR, Carmon JG. Tyrosinase: A comprehensive 
reviewofitsmechanism. BiochimBiophysActa. 1995;1247(1):1-11. https://doi.org/10.1016/0167-4838(94)00204-t

PMid:7873577

5. Kumar S, Pandey AK. Chemistry and biological activities of flavonoids: An overview. Sci World J. 2013;2013:162750. https://doi.org/10.1155/2013/162750

PMid:24470791

6. Batubara I, Darusman LK, Mitsunaga T, Rahminiwati M, Djauhari E. Potency of Indonesian medicinal plants as tyrosinase inhibitor and antioxidant agent. J Biol Sci. 2010;10(2):138-44. https://doi.org/10.3923/jbs.2010.138.144

7. Saraswaty V, Suparta NW, Setiyanto $H$, Rachmawati $H$, Adnyana IK. Transformation of melinjo seed micropowders into nanopowder enhances extractability of phenolic compounds and tyrosinase inhibitory activity. Sains Malaysiana. 2019;48(5):983-90. https://dx.doi.org/10.17576/ jsm-2019-4805-06

8. Ma J, Yang H, Basile MJ, Kennelly EJ. Analysis of polyphenolic antioxidants from the fruit of three Pouteria species by selected ion monitoring liquid chromatography-mass spectrometry. J Agric Food Chem. 2004;52(19):5873-8. https://doi. org/10.1021/jf049950k

\section{PMid:15366835}

9. Hernandez CL, Villasenor IM, Joseph E, Tolliday N. Isolation and evaluation of antimitotic activity of phenolic compounds from Pouteria campechiana Baehni. Philippine J Sci. 2008;137(1):1-10.

10. Pourmurad F, Hosseinimehr SJ, Shahabimajd N. Antioxidant activity, phenol and flavonoid contents of some selected Iranian medicinal plants. Afr J Biotechnol. 2006;5(11):1142-5.

11. Chang CC, Yang MH, Wen HM, Chem JC. Estimation of total flavonoid content in propolis by two complementary colorimetric methods. J Food Drug Anal. 2002;10(3):178-82. http://doi. org/10.38212/2224-6614.2748

12. Masuda T, Yamashita D, Takeda Y, Yonemori S. Screening for tyrosinase inhibitors among extract of seashore plants and identification of potent inihibitors from Garcinia subelliptica. Biosci Biotechnol Biochem. 2005;69(1):197-201. https://doi. org/10.1271/bbb.69.197

\section{PMid:15665485}

13. Blois MS. Antioxidant determinations by the use of a stable free radical. Nature 1958;181:1199-200.

14. Scherer R, Godoy HT. Antioxidant activity index (AAI) by the 2,2-diphenil-1-picrylhydrazyl method. Food Chem 2009;112:654-8. https://doi.org/10.1016/j.foodchem.2008.06.026

15. Tanase C, Cosarca S, Muntean DL. A critical review of phenolic compounds extracted from the bark of woody vascular plants and their potential biology activity. Molecules. 2019;24(1182):1182. http://doi:10.3390/molecules24061182

\section{PMid:30917556}

16. Treml J, and Smejkal K. Flavonoids as potent scavengers of hydroxyl radicals. Compr Rev Food Sci Food Saf. 2016;15(1):720-38. https://doi.org/10.1111/1541-4337.12204

17. Chen CY, Lin LC, Yang WF, Bordon J, Wang HMD. An update organic classification of tyrosinase. Curr Org Chem. 2015;19(1):4-18. http://doi:10.2174/1385272819666141107224 800036

18. Kim YJ, Uyama H. Review: Tyrosinase inhibitors from natural and synthetic sources: Structure, inhibition mechanism and perspective. Cell Mol Life Sci. 2005;62(15):1707-23. http:// doi:10.1007/s00018-005-5054-y PMid: 15968468

19. Rao GV, Sahoo MR, Madhavi MS, Mukhopadhay T. Phytoconstituents from the leaves and seeds of Manilkara zapota Linn. Pharm Lett. 2014;6(2):69-73.

20. Baky MH, Kamal AK, Elgindi MR, Haggag EG. A review on phenolic compounds from family sapotaceae. J Pharmacogn Phytochem. 2016;5(2):280-7.

21. Hardiyanti R, Marpaung L, Andyana IK, Simanjuntak P. Isolation of quercitrin from Dendrophthoe pentandra (L.) and it's antioxidant and antibacterial activities. Rasayan J Chem. 2019;12(4):1822-7. http://dx.doi.org/10.31788/RJC.2019.1235353

22. Yin Y, Li W, Son Y, Sun L, Lu J, Kim D, et al. Quercitrin protects skin from UVB-induced oxidative damage. Toxicol Appl Pharmacol. 2013;269(2):88-99. http://dx.doi.org/10.1016/j. taap.2013.03.015

PMid:23545178 